\title{
RA?EGA
}

O ESPACO GEOGRÁFICO EM ANÁLISE

\section{IMPACTO AMBIENTAL SONORO NO TRECHO SUL DA LINHA VERDE NA CIDADE DE CURITIBA, PARANÁ, BRASIL}

\section{ENVIRONMENTAL NOISE IMPACT IN THE SOUTH SECTION OF THE GREEN LINE IN THE CITY OF CURITIBA, PARANÁ, BRAZIL}

\author{
Fernando Bunn \\ Laboratório de Acústica Ambiental, Industrial e Conforto Acústico \\ Universidade Federal do Paraná - UFPR \\ Curitiba, PR, Brasil \\ e-mail: fernandobunn@hotmail.com
}

Marcus Manfrin Oliveira Filho Laboratório de Acústica Ambiental, Industrial e Conforto Acústico Universidade Federal do Paraná - UFPR

Curitiba, PR, Brasil e-mail: marcus.oliveira.filho@gmail.com

Paulo Henrique Trombetta Zannin Laboratório de Acústica Ambiental, Industrial e Conforto Acústico Universidade Federal do Paraná - UFPR Curitiba, PR, Brasil e-mail:paulo.zannin@gmail.com

\section{Resumo}

O presente estudo apresenta a avaliação do impacto sonoro gerado na Linha Verde trecho sul. Para realização deste estudo, foram efetuadas medições em 24 pontos em uma extensão total de $14 \mathrm{~km}$ - a partir do Contorno Sul até o Jardim Botânico. A partir de todas as informações obtidas neste estudo concluiu-se que o tráfego de veículos na Linha Verde - Trecho Sul produz um impacto ambiental que resulta em níveis de poluição sonora inadequados para as pessoas que vivem ou trabalham em torno desta via. O nível de ruído para todos os 24 pontos analisados está acima dos valores aceitos pela lei municipal de Curitiba 10.625:02, ou seja, está acima de $65 \mathrm{~dB}(\mathrm{~A})$ no período diurno. Através do estudo observou-se que a geração de ruído no local é constante e intensa, sendo o ruído fundamentalmente gerado pelo fluxo intenso de veículos leves (carros de passeio, utilitários e motocicletas) e veículos pesados (caminhões, ônibus). Os mapas acústicos mostraram ser uma ferramenta 
importante na caracterização de áreas atingidas pelo ruído. Mapas acústicos de cenários hipotéticos foram simulados, variando-se a velocidade média da via, o tipo de pavimento e a composição da frota. Através da análise destes cenários, percebe-se que a melhoria em relação à poluição sonora está ligada diretamente a questões de planejamento e infraestrutura, sendo então necessária a parceria entre órgãos governamentais de planejamento, desenvolvimento urbano, transportes, meio ambiente, educação e comunidade científica para a mitigação do impacto causado pela poluição sonora e, consequentemente, a melhoria da qualidade vida das pessoas que habitam o meio ambiente urbano.

Palavras chave: poluição sonora, impactos ambientais, Linha Verde, medições sonoras, mapeamento acústico.

\begin{abstract}
This study involved an evaluation of the noise impact generated on the south section of the Green Line expressway. Measurements were taken at 24 points along a $14 \mathrm{~km}$ stretch, from the South Section to the Botanical Garden neighborhood. Based on the overall information garnered in this study, it was concluded that the vehicle traffic on the Green Line - South Section generates an environmental impact that results in unacceptable levels of noise pollution for the people who live or work in the surroundings of this expressway. The noise level at the 24 analyzed points exceeds the values specified by Curitiba Municipal Law 10625/2002, i.e., it is above $65 \mathrm{~dB}(\mathrm{~A})$ during the daytime. This study revealed that the noise in the area is constant and intense, and that it is generated mainly by the intense flow of light vehicles (passenger cars, SUVs and motorcycles) and heavy vehicles (trucks and buses). Acoustic mapping proved to be an important tool for the characterization of areas affected by noise. Acoustic maps of hypothetic scenarios were simulated, varying the expressway average speed, pavement type and the vehicle composition. Based on all the analyses, it can be stated that any mitigation of noise pollution must be directly linked to issues of planning and infrastructure. This will require a partnership between the municipal departments of planning, urban development, transport, environment, education and the scientific community to ameliorate this environmental concern and thereby improve the quality of life of those who live in this region.
\end{abstract}

Keywords: noise pollution, environmental impacts, Green Line, acoustic measurements, noise mapping.

\title{
1. INTRODUÇÃO
}

Os números crescentes da população e de veículos ocasionaram 0 aparecimento e a necessidade de estudos de um novo componente na vida 
das cidades: o ruído urbano. Atualmente o ruído já é classificado como um tipo de poluição tóxica (SANTOS DE SOUZA, 2000).

Vários estudos relacionam a poluição sonora a problemas de saúde, como: irritabilidade, baixa concentração, insônia e dor de cabeça (GRIFFITHS E LANGDON (1968); BELOJEVIC \& JAKOVLEVIC, 1997; ZANNIN et al., 2001).

$\mathrm{Na}$ cidade de Curitiba, em entrevistas realizadas com 863 pessoas, as mesmas consideraram o ruído de tráfego urbano como a principal fonte de desconforto ambiental (ZANNIN et al., 2002; PAZ et al., 2005). Em outras cidades brasileiras o ruído gerado pelo trafego de veículos, em Florianópolis (Alves Filho et al., 2004), e o ruído e seus efeitos sobre a população, em São Paulo (Paiva-Vianna \& Cardoso, 2015), também foram estudados.

Em decorrência do grande crescimento populacional das últimas décadas do município de Curitiba, houve a ocupação de áreas antes pouco habitadas. Este fato fez com que áreas às margens da antiga BR-116, situada dentro do perímetro urbano municipal de Curitiba, se transformassem em bairros com densas concentrações demográficas.

Para se ter uma ideia do aumento do número de veículos, em abril de 2007 a frota curitibana era de 985.558 veículos e em abril de 2010 a frota curitibana de veículos já alcançava um total de 1.164 .752 veículos, ou seja, um aumento de mais de $18 \%$ em apenas 3 anos (DETRAN/PR, 2007).

A Linha Verde passa por um processo de reurbanização, o qual trará benefícios em diversas áreas para cidade de Curitiba, sendo destacados: a melhoria da segurança viária, aumento da rede de transporte coletivo e o incentivo a construção de edifícios habitacionais, hoje ainda praticamente inexistente, pois para a população em geral a região abrangida pela Linha Verde é local da circulação de caminhões e, consequentemente, barulhento (Gazeta do Povo, 2015). O trafego de caminhões pesados por sua vez já está sendo deslocado para o contorno leste da cidade, e os mesmos são proibidos de circular pela Linha Verde em determinados períodos do dia, como por exemplo, o noturno (ZANNIN e SANT'ANA, 2011; BUNN e ZANNIN, 2015).

O presente artigo tem como objetivo a apresentação e caracterização do problema da poluição sonora no trecho sul da Linha Verde, através de 
medições in situ, e também através do cálculo dos mapas de ruído. Os mapas de ruído são hoje ferramentas fundamentais para o estudo da poluição sonora em grandes centros urbanos, conforme ilustrado a seguir.

Bressane et.al. (2015) propuseram uma metodologia para a gestão e controle da poluição sonora baseada no zoneamento ambiental acústico. Os autores concluíram que: "o zoneamento ambiental acústico pode contribuir com o avanço em soluções aplicáveis ao controle da poluição sonora, colaborando para o alcance de cidades saudáveis e sustentáveis".

Zannin e Sant'Ana (2011) estabeleceram um sistema de medição onde os níveis de pressão sonora eram medidos a cada $500 \mathrm{~m}$, sendo estas medições repetidas a cada três meses durante três anos. Os pesquisadores fizeram também projeções para o futuro, as quais apontaram o impacto sonoro provocado por veículos pesados na Linha Verde de Curitiba. Hoje, no entanto, ao contrário do apresentado em 2011 (Zannin e Sant'Ana, 2011), foi mostrado que já existe uma limitação para a circulação de veículos pesados na Linha Verde (Bunn e Zannin, 2015). Os autores ressaltam que a tendência é eliminar o tráfego de veículos pesados nesta via, restando somente os ônibus da rede integrada do município de Curitiba.

Szeremeta e Zannin (2009) estudaram a paisagem sonora de parques públicos em Curitiba. O estudo apontou que há uma forte influência do ruído de tráfego em todos os parques, já que mais de $50 \%$ dos pontos avaliados apresentaram níveis de pressão sonora em desacordo ao permissível por lei. Conceitua-se paisagem sonora (ou "soundscape", em inglês) como o estudo dos níveis sonoros integrados à paisagem geográfica. Este termo foi cunhado por R. Murray Schafer em seu livro "The Tuning of the World", 1977. Há também uma versão traduzida para o português desta obra (Schafer, 1997).

Paz e Zannin (2010) desenvolveram métodos matemáticos para o cálculo dos níveis sonoros na Linha Verde no período diurno. Em Paz e Zannin (2014) encontramos o desenvolvimento de modelos matemáticos para o cálculo dos níveis sonoros no período noturno. 


\section{MATERIAIS E MÉTODOS}

As etapas adotadas para o estudo de impacto ambiental sonoro, na implantação do Trecho Sul da Linha Verde, são listadas a seguir: 1) Levantamento do local; 2) Reconhecimento das fontes de ruído existentes no local; 3) Realização de medições dos níveis de pressão sonora equivalente $L_{e q}$ ponderados na escala "A" e expressos em dB(A); 4) Contagem do fluxo de veículos; 5) Elaboração dos mapas de ruído; 6) Análise dos resultados.

Em Curitiba, a Lei Municipal 10.625/02 dispõe sobre ruídos urbanos, proteção do bem estar e do sossego público. A Linha Verde está inserida em uma região da cidade de Curitiba denominada Zona de Transição - BR 116 e Setor Especial - BR 116, conforme a Tabela 1 (PMC, 2002).

TABELA 1: LIMITES MÁXIMOS PERMISSÍVEIS DE RUÍDO - LEI MUNICIPAL 10.625/02 $\left(\mathrm{L}_{\text {Aeq }}\right)$

\begin{tabular}{cccc}
\hline & Diurno & Vespertino & Noturno \\
Zonas de Uso & $7: 01-$ & $19: 01-$ & $22: 01-$ \\
& $19: 00$ & $22: 00$ & $7: 00$ \\
& Horas & Horas & Horas \\
\hline \multirow{2}{*}{ ZT-BR116 e SE-BR116 } & $65 \mathrm{~dB}(\mathrm{~A})$ & $60 \mathrm{~dB}(\mathrm{~A})$ & $55 \mathrm{~dB}(\mathrm{~A})$ \\
& & & \\
\hline
\end{tabular}

Para as medições se adotou um trecho de 12 quilômetros de extensão, com monitoramento em 24 pontos distanciados entre si em 500 m (INAV/GEOSISTEMAS SRL, 2009 IN GOOGLE EARTH FOR WINDOWS V.5.2, 2010). A distribuição dos pontos começa no Contorno Sul até o Jardim Botânico, conforme apresentado nas Figuras 1 até 6 


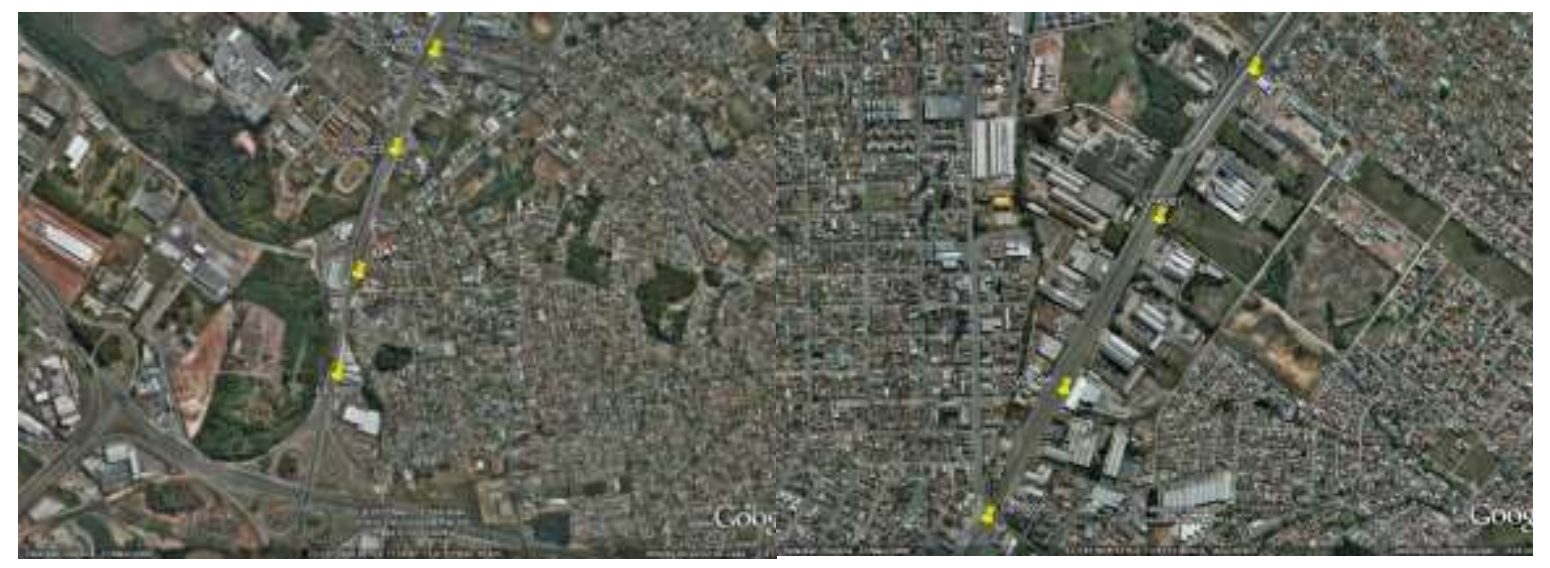

FIGURA 1: DISTRIBUIÇÃO DOS PONTOS 1 AO 4 DO TRECHO SUL DA LINHA VERDE
FIGURA 2: DISTRIBUIÇÃO DOS PONTOS 5 AO 8 DO TRECHO SUL DA LINHA VERDE

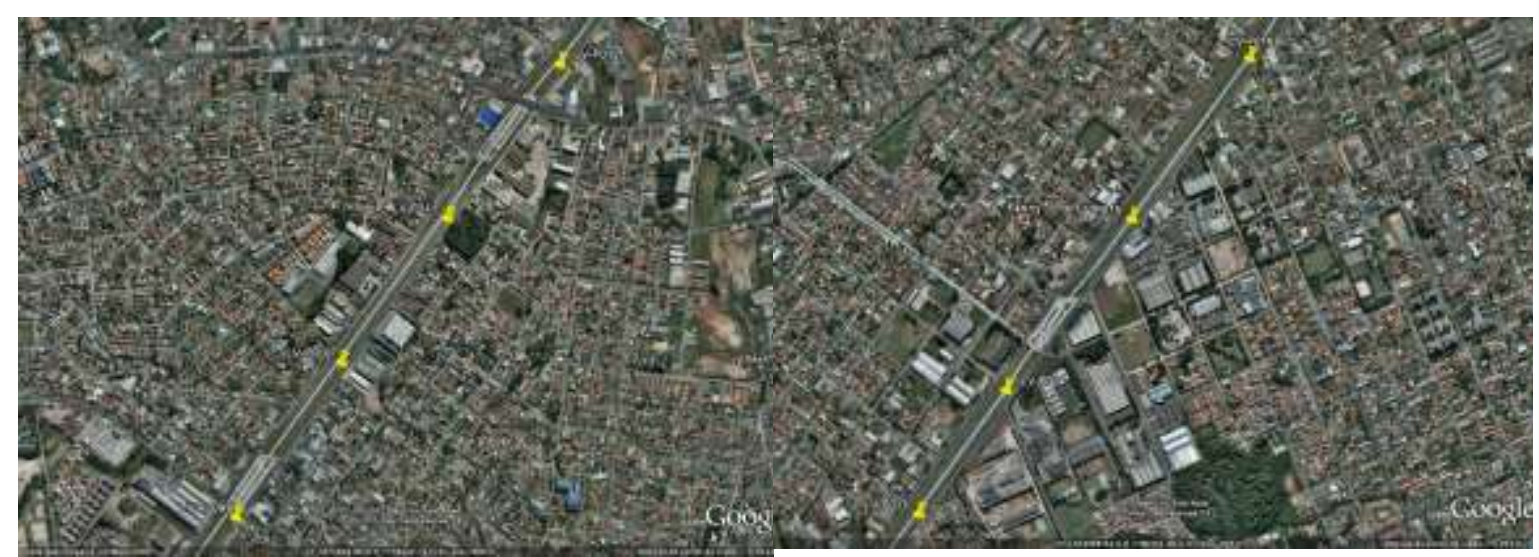

FIGURA 3: DISTRIBUIÇÃO DOS PONTOS 9 AO 12 DO TRECHO SUL DA LINHA VERDE
FIGURA 4: DISTRIBUIÇÃO DOS PONTOS 13 AO 16 DO TRECHO SUL DA LINHA VERDE 


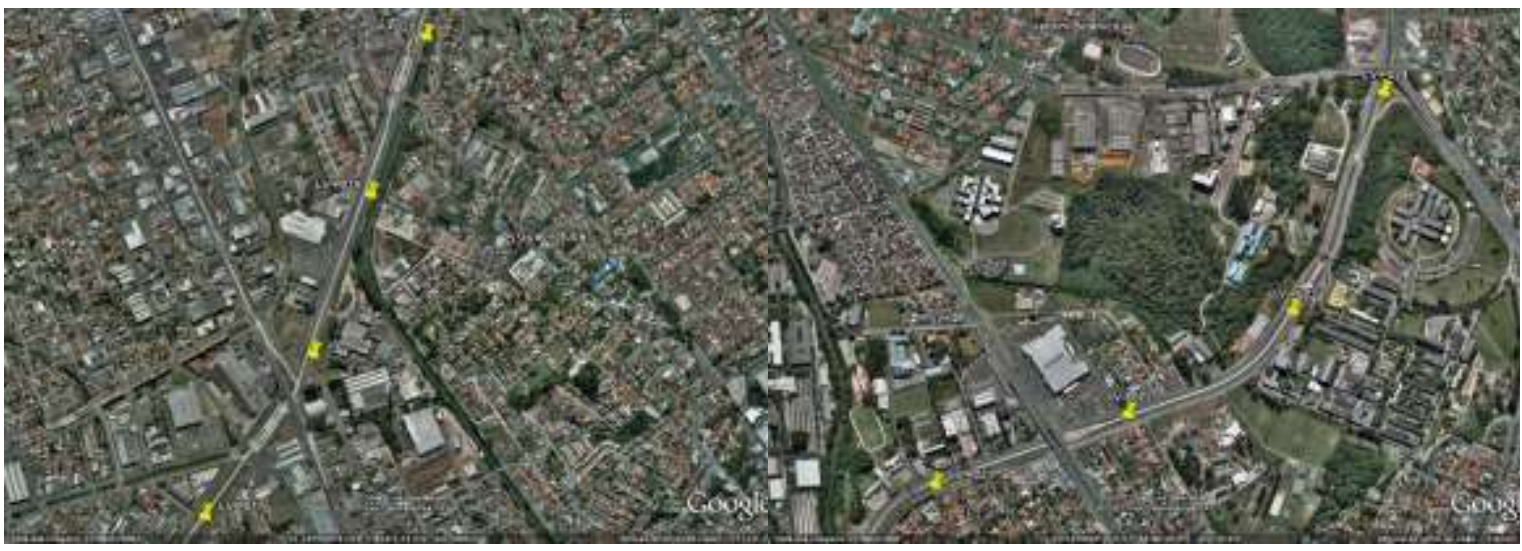

FIGURA 5: DISTRIBUIÇÃO DOS PONTOS 17 AO 20 DO TRECHO SUL DA LINHA VERDE
FIGURA 6: DISTRIBUIÇÃO DOS PONTOS 21 AO 24 DO TRECHO SUL DA LINHA VERDE

Os equipamentos utilizados na realização do estudo foram: 1) medidor de pressão sonora tipo B\&K 2250; 2) Software B\&K Predictor 7810 versão 6.2 para o mapeamento acústico. $O$ tempo de medição foi de 15 minutos e a contagem de veículos foi realizada visualmente e computada em uma planilha durante este período, sendo o fluxo separado em motos, veículos leves e veículos pesados (ônibus e caminhões) (ZANNIN e SANT'ANA, 2011, ROMEU et. al., 2011; ZANNIN et.al., 2013). As medições foram feitas conforme recomendado pela norma alemã RLS - 90 - RICHTLINIEN FÜR DEN LÄRMSCHUTZ AN STRASSEN - (Diretrizes para o controle do ruído em rodovias), (1990), utilizada para avaliação do ruído em rodovias, a qual indica que o medidor de nível de pressão sonora deve ser posicionado a 25 metros do centro da via.

A estimativa de velocidade média foi realizada através da condução de um veículo no trecho, verificando-se pelo velocímetro a velocidade média aproximada em cada ponto para veículos leves, motos e veículos pesados.

De posse destes dados, foi criado um modelo computacional - mapas acústicos da região em estudo - utilizando-se o software B\&K Predictor 7810, baseado nas rotinas de cálculo da norma ISO 9613-2 (1996). O equacionamento contido na norma possibilita a determinação do nível de pressão sonora equivalente em ambientes externos, considerando efeitos 
como a atenuação sonora durante a propagação, correções para a absorção atmosférica, efeitos da topografia do solo, obstáculos, absorção do solo, entre outros.

Também foram inseridos os dados para as curvas de nível ao longo do trecho. Para esta etapa utilizaram-se dados do IPPUC (Instituto de Pesquisa e Planejamento Urbano de Curitiba), obtidos através da base de dados denominada Curitiba Digital - Edição 2006/CD-ROM. O programa utiliza ferramentas na base SIG (Sistema de Informações Geográficas).

Com a altimetria presente no modelo, são inseridas em seguida as ortofotos com intuito de digitalizar as edificações e a vegetação, inserindo a estes uma altura. O principal empecilho para digitalização das edificações e da vegetação foi a grande quantidade a serem digitalizadas - mais de $4500 \mathrm{em}$ todo o Trecho Sul. Com estes dados, é possível gerar uma visualização em três dimensões do modelo [Figura 7].

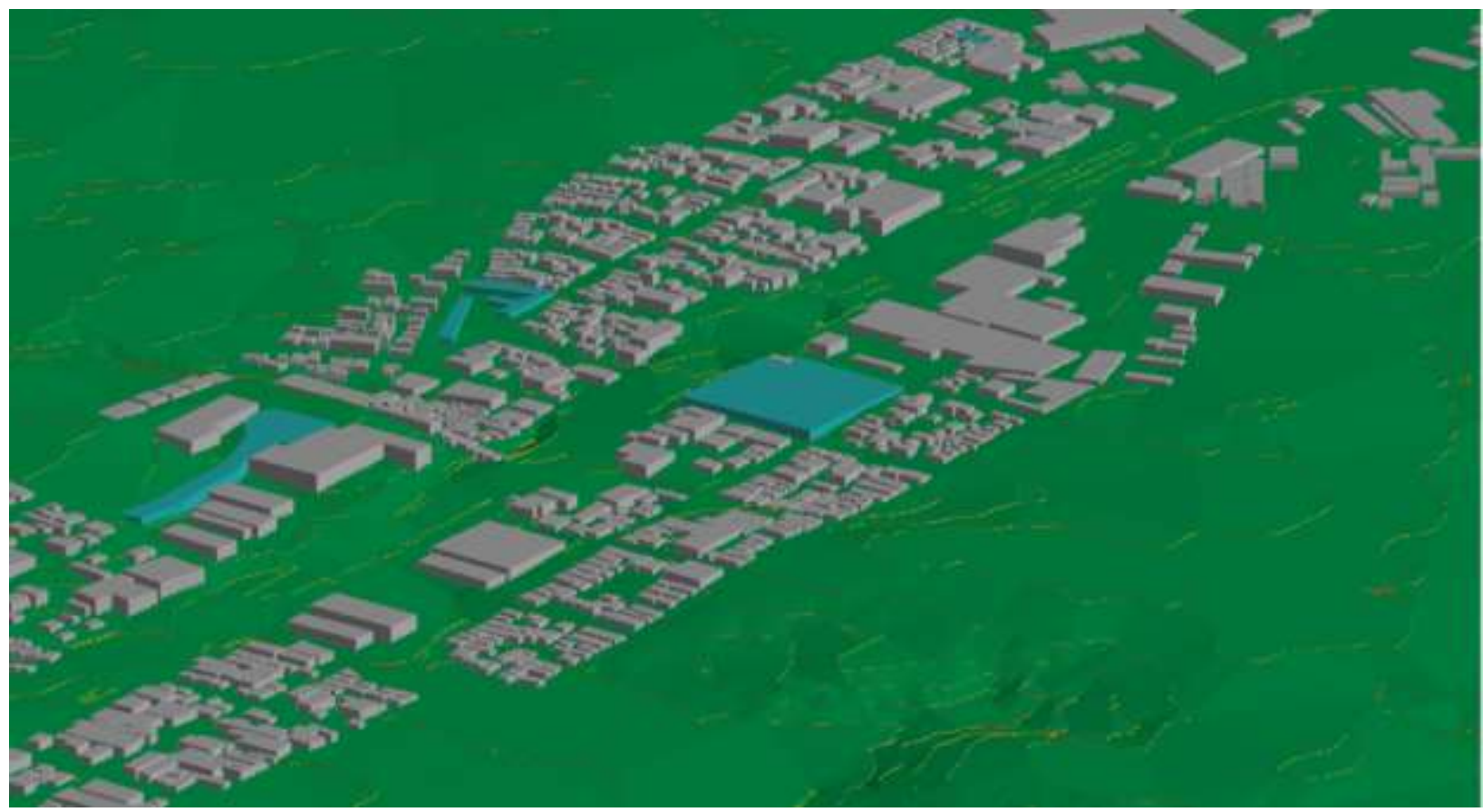

FIGURA 7: VISUALIZAÇÃO DAS EDIFICAÇÕES E VEGETAÇÃO DO MODELO EM 3 DIMENSÕES

Por fim, inserem-se dados de tráfego computados manualmente ao modelo. Escolhe-se uma área de cálculo a qual se deseja fazer o mapeamento 
acústico com um grid de 20 em 20 metros e altura de 4 metros (MURPHY e KING, 2010; MURPHY e KING, 2011). Com todos estes dados inseridos no software, os níveis de pressão sonora equivalentes são calculados, conforme mostrado a seguir.

Para a calibração do modelo, utilizou-se como referência as recomendações do EUROPEAN COMMISSION WORKING GROUP ASSESSMENT OF EXPOSURE TO NOISE (WG-AEN, 2006, p1-129), para a qual, a diferença aceita entre os valores medidos e simulados é de (+/-) 4,6 $\mathrm{dB}(\mathrm{A})$ (BIES e HANSEN, 2002; WG-AEN, 2006).

\section{RESULTADOS E DISCUSSÃO}

Através dos resultados das medições, foram obtidos os níveis de pressão sonora equivalente $\left(L_{e q}\right)$, sendo em seguida calculados os mapas acústicos para os 24 pontos estudados ao longo do trecho sul da Linha Verde. As medições são de extrema importância para o estudo, pois além de caracterizar o problema servem também como instrumento de calibração para o modelo de predição acústica.

Antes da apresentação dos resultados das medições acústicas e dos mapeamentos, apresentam-se os resultados obtidos para contagem de veículos e estimativa de velocidade, que são parâmetros fundamentais para a realização do estudo. A Tabela 2 e a Figura 8 a seguir apresentam a composição geral do tráfego de veículos para a Linha Verde - Trecho Sul.

TABELA 2: COMPOSIÇÃO GERAL DE VEÍCULOS NA LINHA VERDE TRECHO SUL

\begin{tabular}{cccc}
\hline & Motos & Veículos leves & $\begin{array}{c}\text { Veículos } \\
\text { pesados }\end{array}$ \\
\hline $\begin{array}{c}\text { Média de } \\
\text { veículos/hora } \\
\text { Total em \% }\end{array}$ & 258 & 1869 & 492 \\
\hline
\end{tabular}




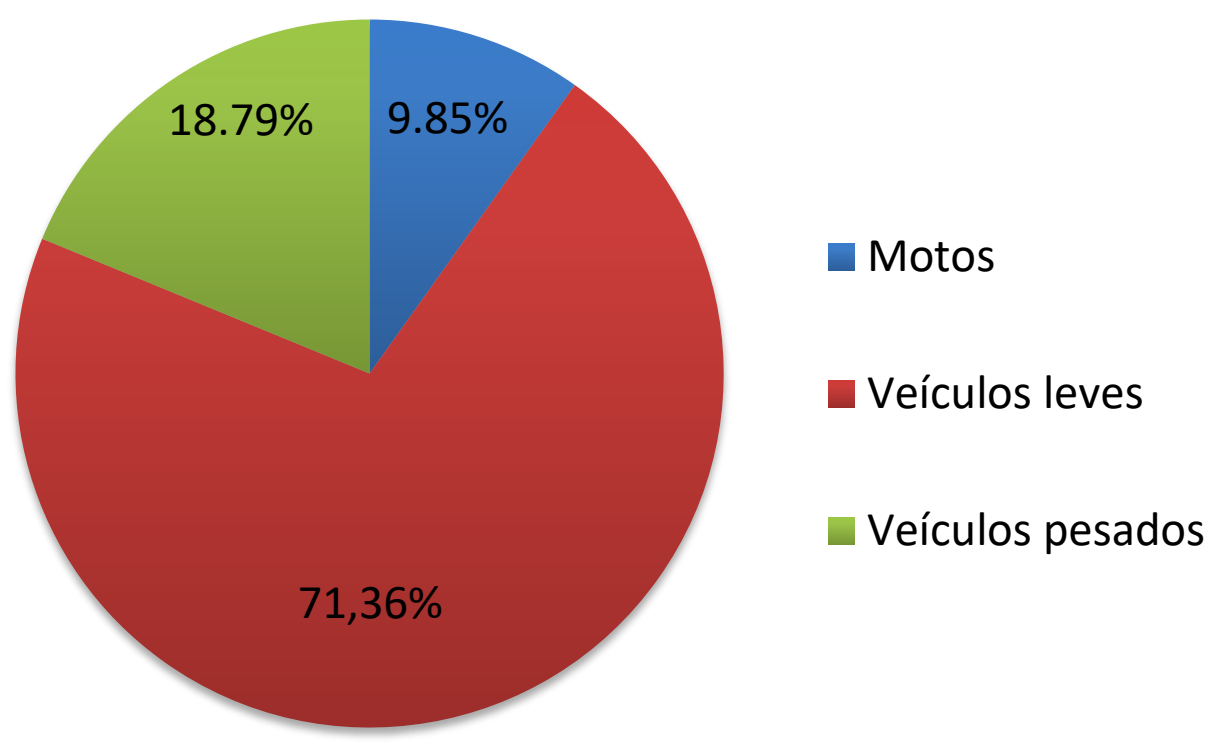

\section{FIGURA 8: COMPOSIÇÃO GERAL DO TRÁFEGO NA LINHA VERDE - TRECHO SUL}

Para o Trecho Sul da Linha Verde, a grande porcentagem do fluxo baseia-se praticamente em veículos leves. Entretanto, quase $1 \mathrm{em}$ cada 5 veículos que passam são veículos pesados, os quais são muito mais ruidosos (BRAMIGK et. al., 1992). Devido a este fator, a composição do fluxo é de grande importância para o estudo realizado.

Outro parâmetro avaliado para caracterização do fluxo foi a velocidade média para cada ponto do trecho analisado. Os resultados das estimativas da velocidade média para o trecho sul da Linha Verde ficaram: 1) Motos: $70 \mathrm{~km} / \mathrm{h}$; 2) Veículos leves: $70 \mathrm{~km} / \mathrm{h}$; 3) Caminhões: $60 \mathrm{~km} / \mathrm{h}$.

Foram medidos os níveis sonoros equivalentes $L_{e q}$ expressos em $d B(A)$. A Tabela 3 apresenta o resultado das medições: 
TABELA 3: NÍVEL DE PRESSÃo SONORA EQUIVALENTE EM CADA PONTO - LEQ

\begin{tabular}{|c|c|}
\hline Ponto & $L_{e q}$ em dB(A) \\
\hline 1 & 76,8 \\
\hline 2 & 78,9 \\
\hline 3 & 77,7 \\
\hline 4 & 73,8 \\
\hline 5 & 74,1 \\
\hline 6 & 73,8 \\
\hline 7 & 74,0 \\
\hline 8 & 70,7 \\
\hline 9 & 76,1 \\
\hline 10 & 76,7 \\
\hline 11 & 70,5 \\
\hline 12 & 73,8 \\
\hline 13 & 75,8 \\
\hline 14 & 76,2 \\
\hline 15 & 71,2 \\
\hline 16 & 72,3 \\
\hline 17 & 77,4 \\
\hline 18 & 75,8 \\
\hline 19 & 77,2 \\
\hline 20 & 76,6 \\
\hline 21 & 77,2 \\
\hline 22 & 78,6 \\
\hline 23 & 79,1 \\
\hline 24 & 79,5 \\
\hline
\end{tabular}

A Figura 9 traça um comparativo entre os níveis de pressão sonora equivalente medidos na Linha Verde - Trecho Sul e o limite permitido pela lei municipal 10.625/02 (PMC, 2002, p.15), que é de $65 \mathrm{~dB}(\mathrm{~A})$ : 


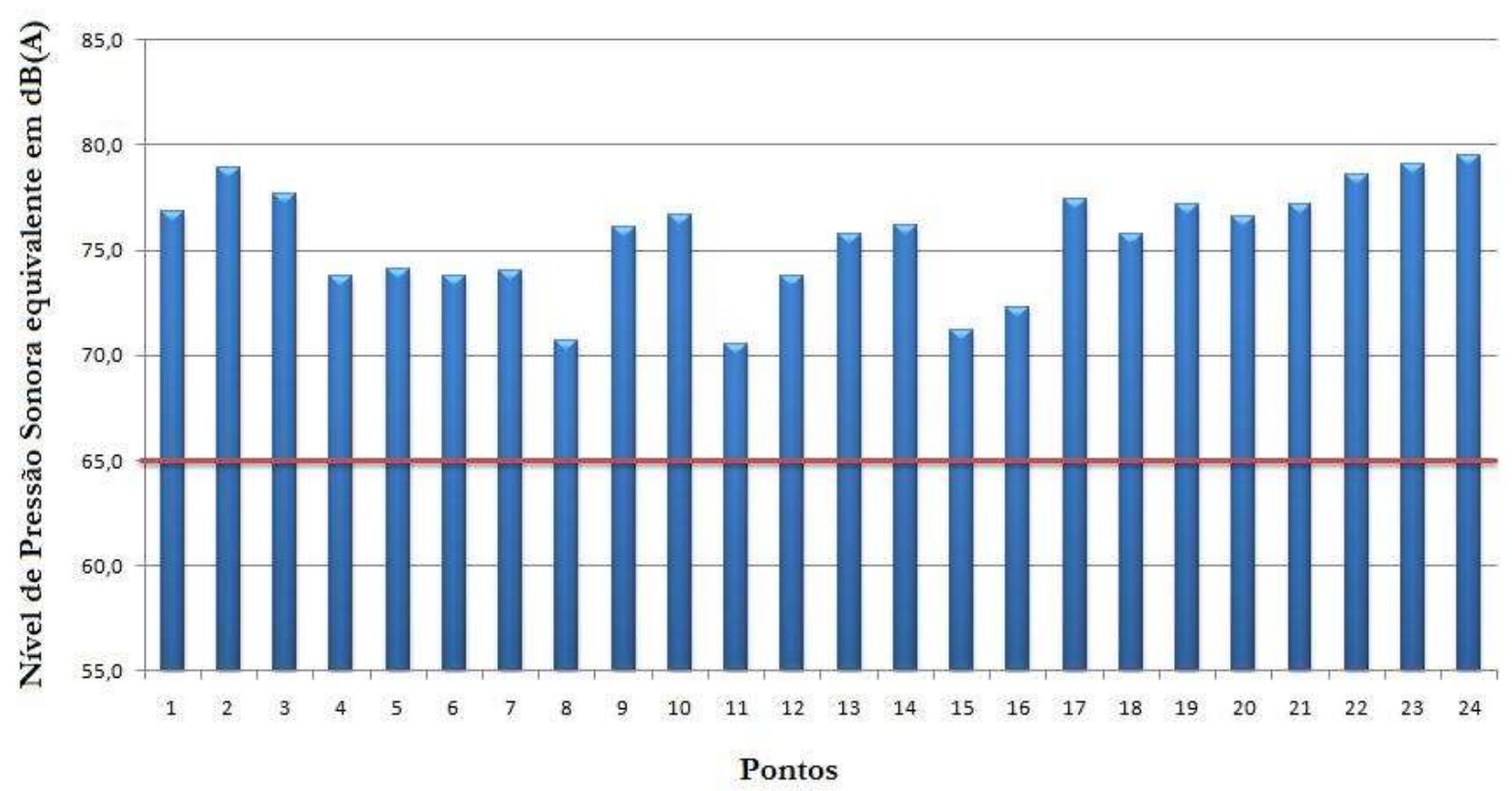

FIGURA 9: NÍVEL DE PRESSÃO SONORA EQUIVALENTE DE ACORDO COM A LOCALIZAÇÃO DO PONTO

Verifica-se que a imissão de ruído em todos os 24 pontos, presentes na Zona de Transição BR-116 e Setor especial BR-116, estão acima do limite de $65 \mathrm{~dB}(\mathrm{~A})$, recomendado pela lei municipal 10.625/02 (PMC, 2002, p15)

Além da composição do tráfego e da velocidade média dos veículos, é inserido no banco de informações do software o tipo de pavimento das ruas do modelo. Com a inclusão desses dados, o mapeamento da Linha Verde trecho sul foi calculado. O mapeamento acústico tem o intuito de apresentar uma visão global do ruído imitido na região avaliada, sendo realizados 24 mapas acústicos para o Trecho Sul da Linha Verde com as seguintes características (Figura 10). 
IMPACTO AMBIENTAL SONORO NO TRECHO SUL DA LINHA VERDE NA CIDADE DE CURITIBA, PARANÁ, BRASIL

\begin{tabular}{|c|c|}
\hline & \\
\hline & Edificações \\
\hline DIDIDA & Vegetação \\
\hline & Curvas de nível \\
\hline & Rodovia \\
\hline & $<45,0 \mathrm{~dB}$ \\
\hline & $45,0-50,0 \mathrm{~dB}$ \\
\hline & $50,0-55,0 \mathrm{~dB}$ \\
\hline & $55,0-60,0 \mathrm{~dB}$ \\
\hline & $60,0-65,0 \mathrm{~dB}$ \\
\hline & $65,0-70,0 \mathrm{~dB}$ \\
\hline & $>70,0 \mathrm{~dB}$ \\
\hline
\end{tabular}

FIGURA 10: LEGENDA UTILIZADA NO MAPEAMENTO ACÚSTICO

A seguir são apresentados os mapas acústicos de alguns dos pontos avaliados:

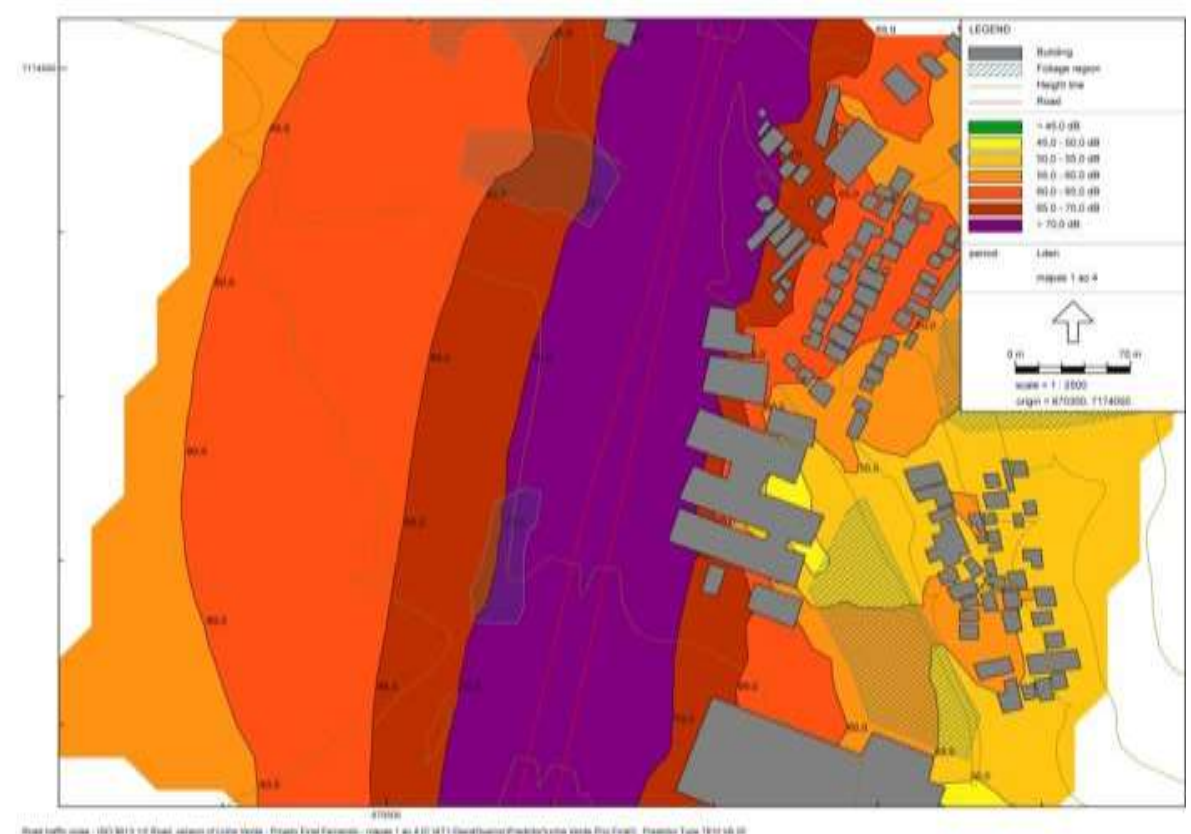

FIGURA 11: NÍVEIS DE PRESSÃO SONORA EQUIVALENTE OBTIDOS ATRAVÉS DE SIMULAÇÃO COMPUTACIONAL PARA O PONTO 1 


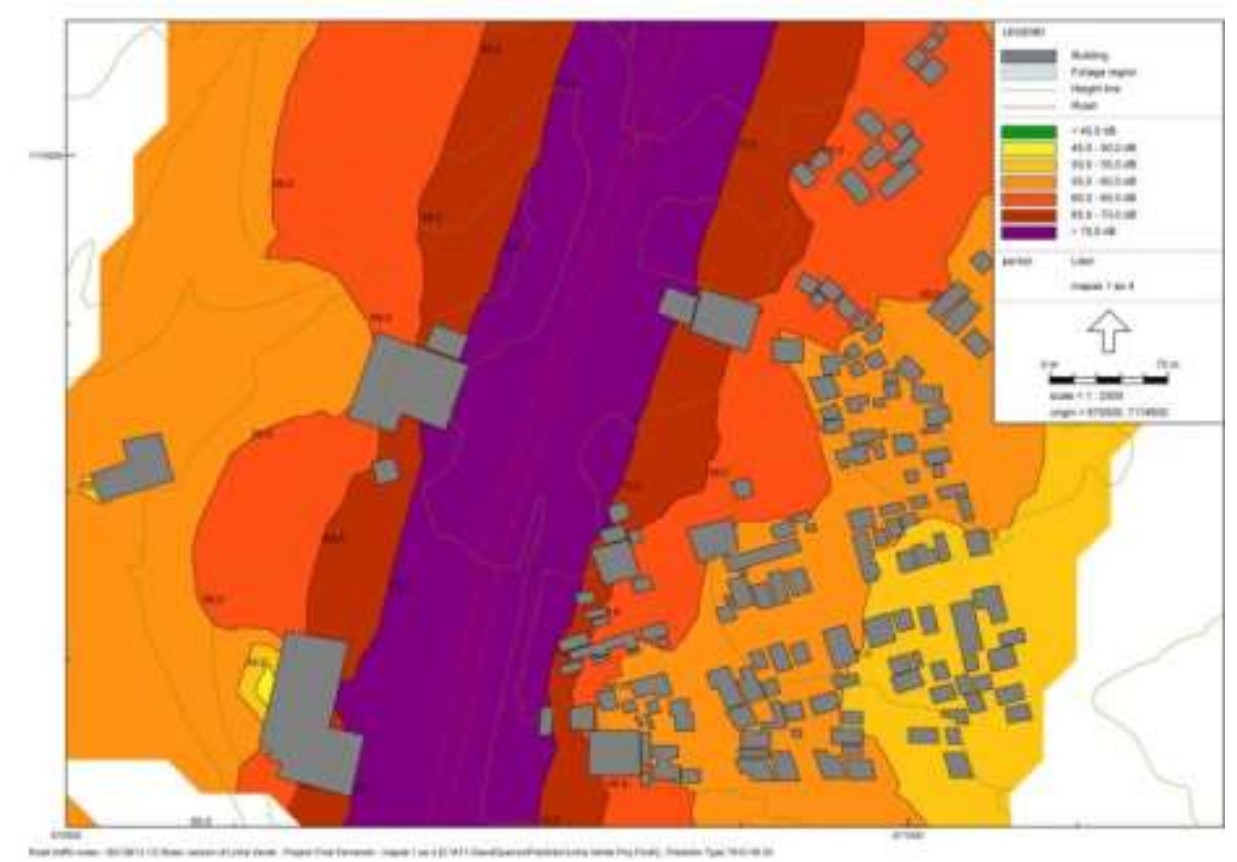

FIGURA 12: NÍVEIS DE PRESSÃO SONORA EQUIVALENTE OBTIDOS ATRAVÉS DE SIMULAÇÃO COMPUTACIONAL PARA O PONTO 2

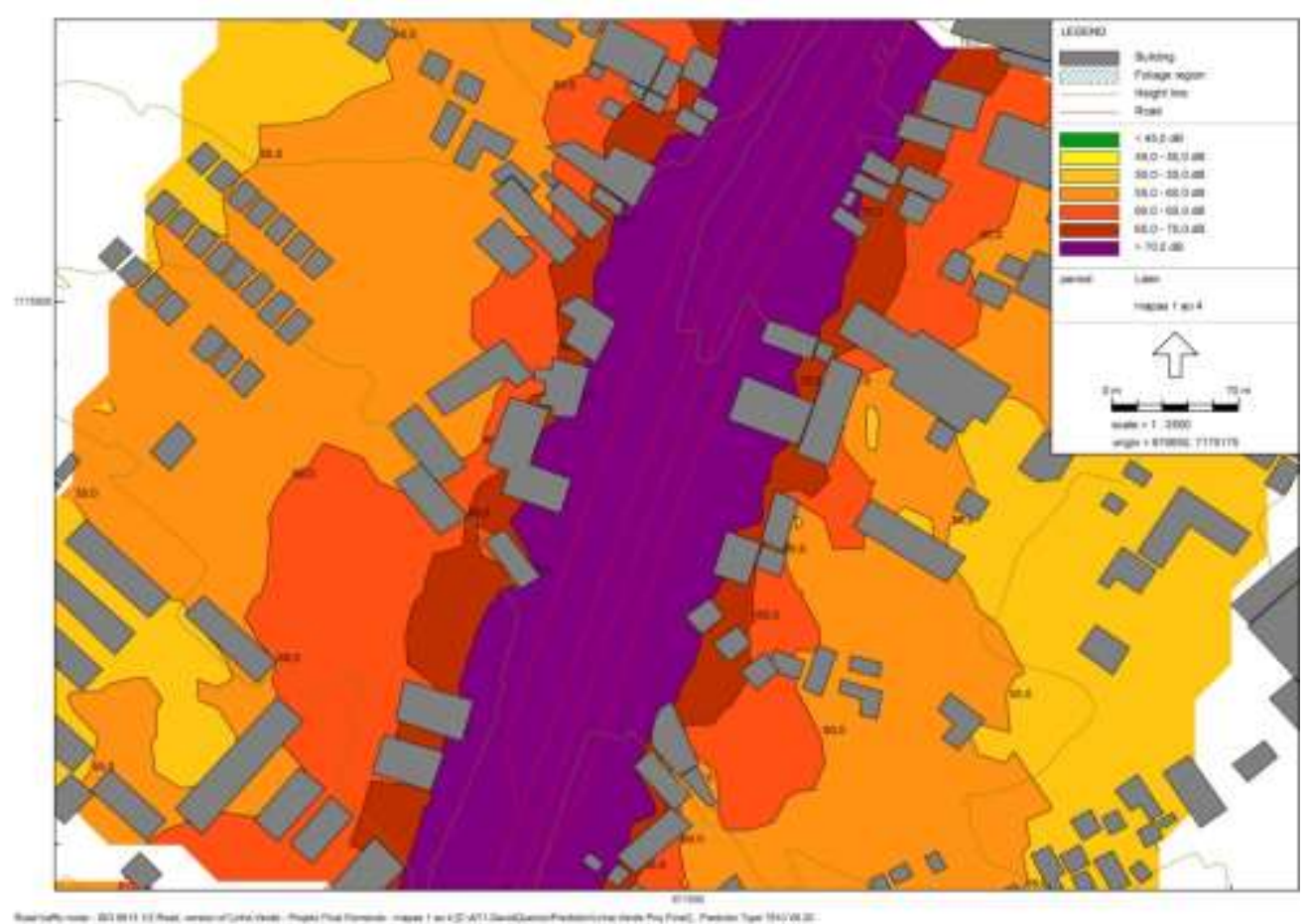

FIGURA 13: NÍVEIS DE PRESSÃO SONORA EQUIVALENTE OBTIDOS ATRAVÉS DE SIMULAÇÃO COMPUTACIONAL PARA O PONTO 3 


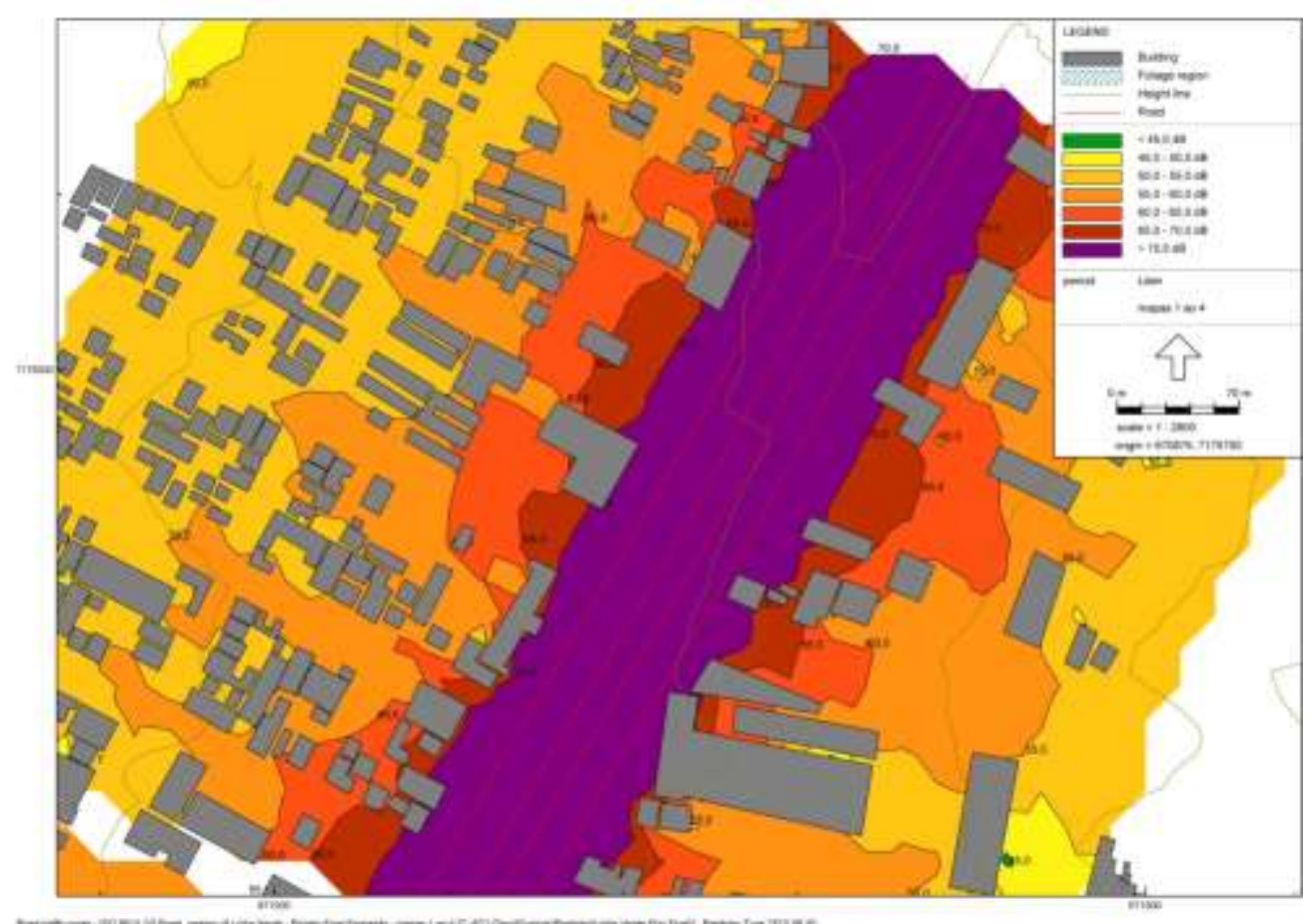

FIGURA 14: NÍVEIS DE PRESSÃO SONORA EQUIVALENTE OBTIDOS ATRAVÉS DE SIMULAÇÃO COMPUTACIONAL PARA O PONTO 4

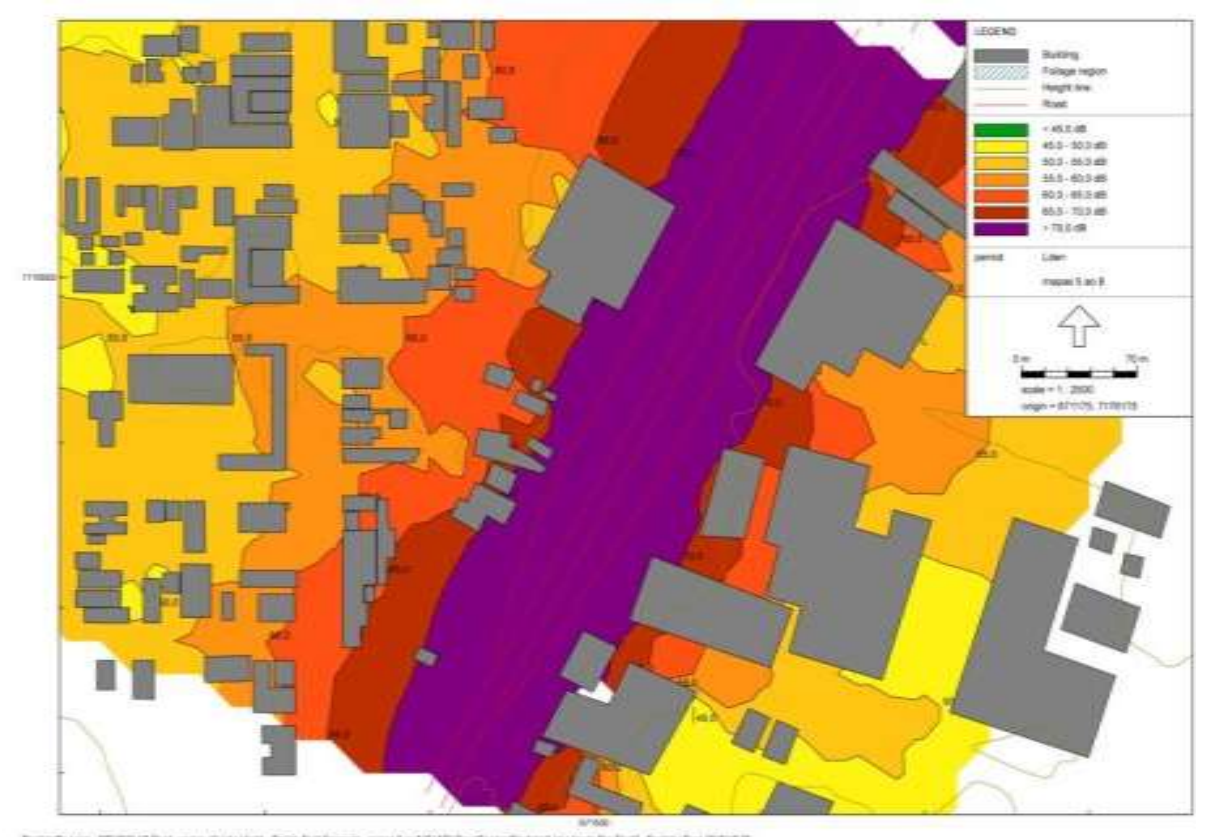

FIGURA 15: NÍVEIS DE PRESSÃO SONORA EQUIVALENTE OBTIDOS ATRAVÉS DE SIMULAÇÃO COMPUTACIONAL PARA O PONTO 5 


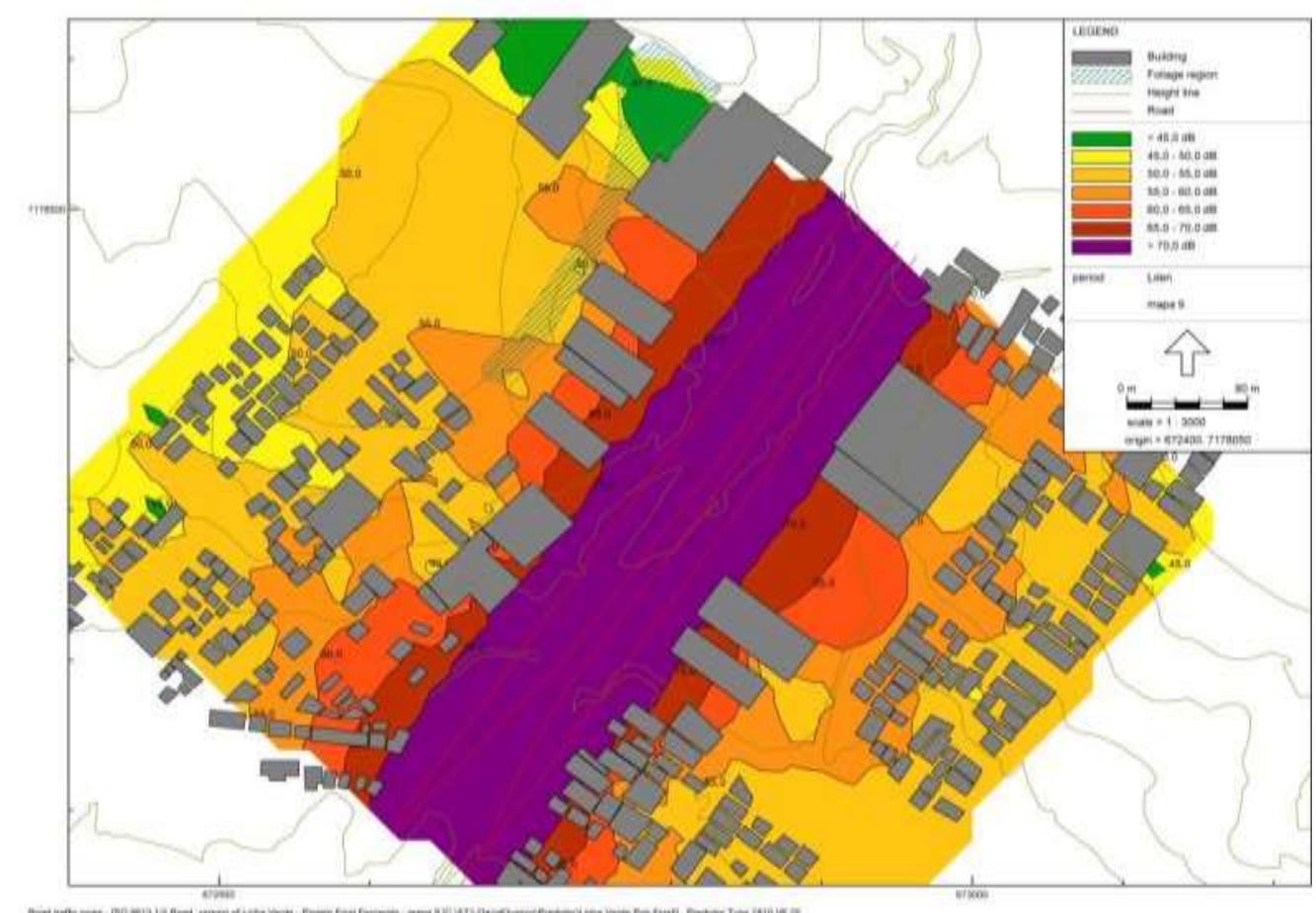

FIGURA 16: NÍVEIS DE PRESSÃO SONORA EQUIVALENTE OBTIDOS ATRAVÉS DE SIMULAÇÃO COMPUTACIONAL PARA O PONTO 9

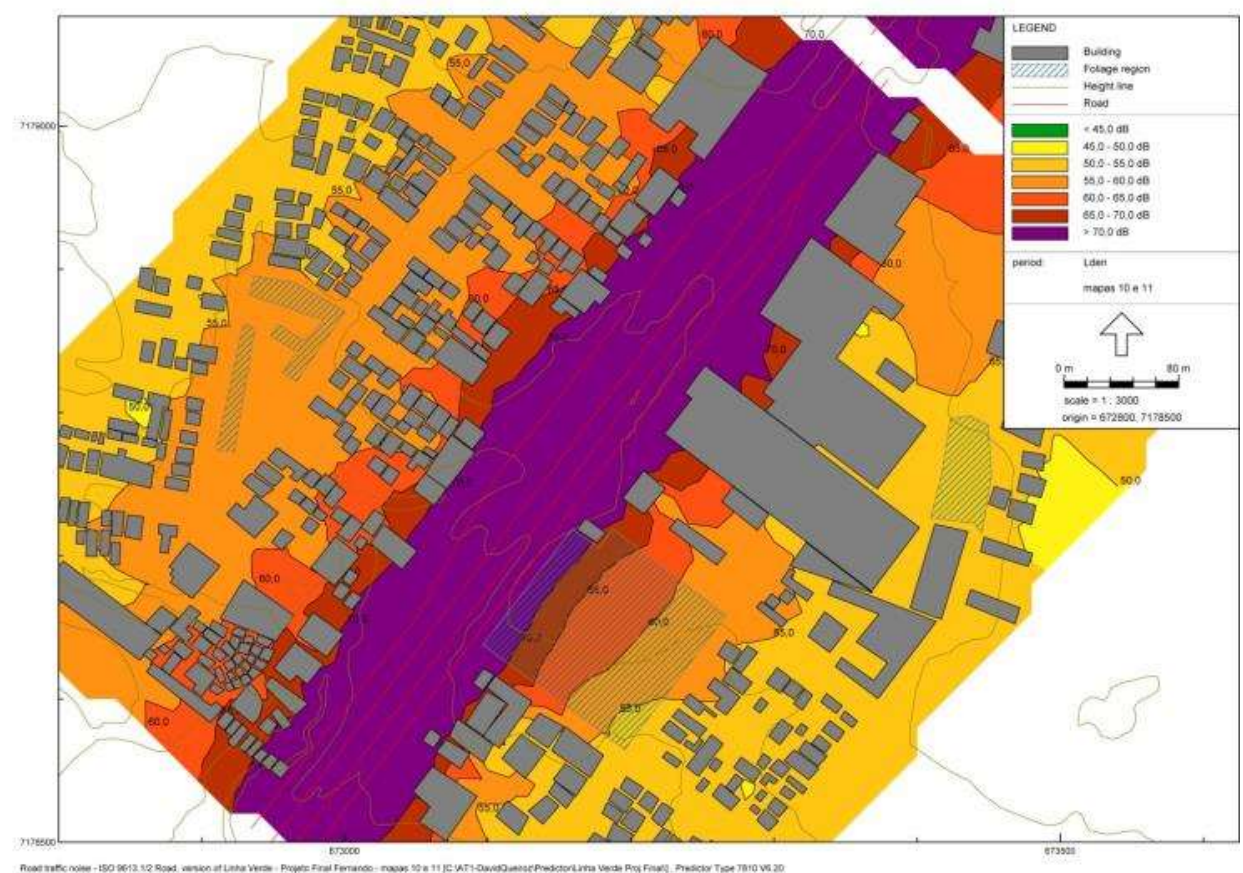

FIGURA 17: NÍVEIS DE PRESSÃO SONORA EQUIVALENTE OBTIDOS ATRAVÉS DE SIMULAÇÃO COMPUTACIONAL PARA O PONTO 10 


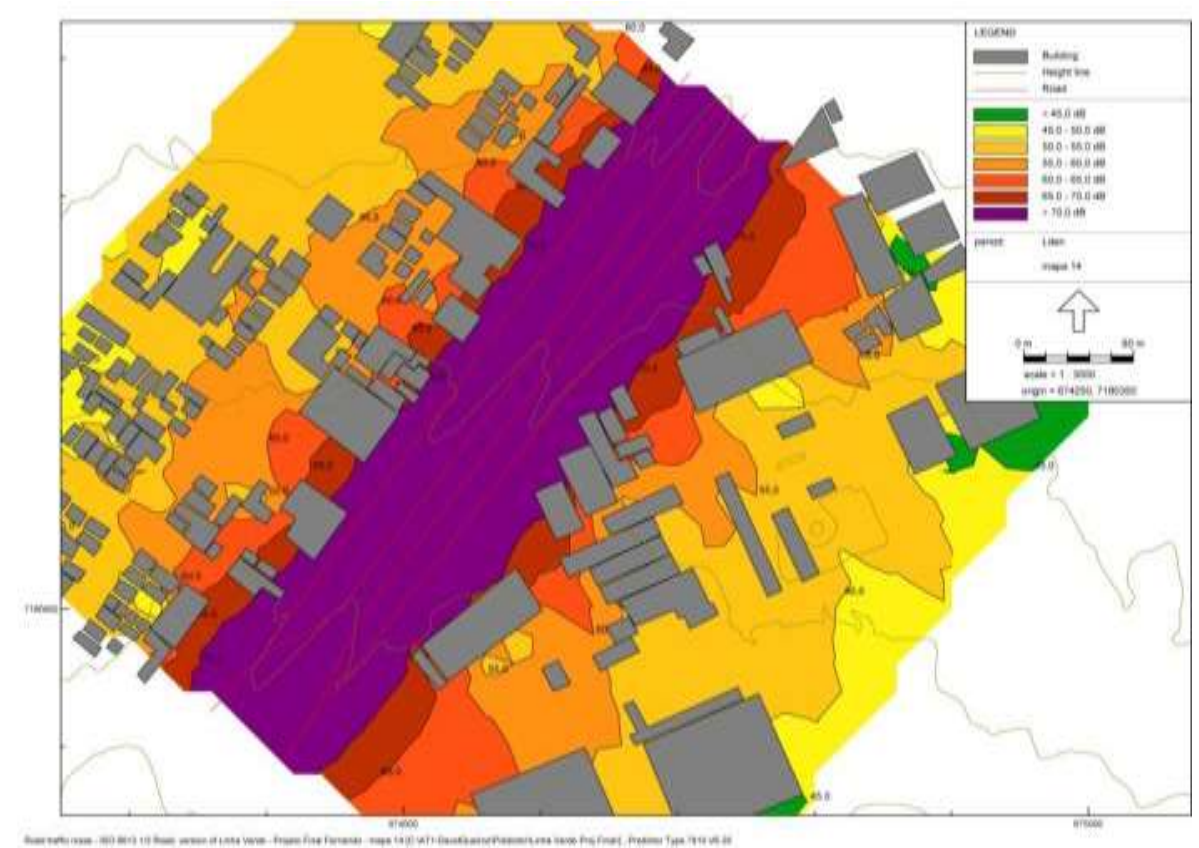

FIGURA 18: NÍVEIS DE PRESSÃO SONORA EQUIVALENTE OBTIDOS ATRAVÉS DE SIMULAÇÃO COMPUTACIONAL PARA O PONTO 14

Percebe-se que todos os mapas diferem entre si, sendo considerados: 0 número de pistas, a densidade habitacional do local, a contagem de veículos leves e pesados para cada ponto e a velocidade média dos veículos.

Os mapeamentos acústicos gerados mostram a dispersão do ruído de tráfego em função da distância, sendo as regiões próximas a rodovia as mais afetadas. As edificações ao longo da rodovia funcionam, em parte, como barreiras acústicas, sendo este barramento mais perceptível a partir do Ponto 04, onde as regiões possuem maior densidade habitacional. Destaca-se, entretanto, que isto configura um problema de saneamento para os moradores destas edificações, já que muitas delas estão situadas em regiões com níveis de pressão sonora equivalentes superiores a $70 \mathrm{~dB}(\mathrm{~A})$. Estas situações são bastante perceptíveis nos mapas dos pontos 05, 09, 10 e 14, por exemplo.

Em contrapartida, em locais onde a densidade habitacional é menor, os níveis sonoros são mais elevados e se propagam a uma distância muito maior. Este fato é verificável pela observação dos mapas referentes aos pontos 01,02 e 03. 
Em comparação com a Lei Municipal 10.625/02, percebe-se que, em todos os casos simulados, o nível de pressão sonora equivalente nos locais próximos a rodovia foram maiores que o permitido, ou seja, níveis sonoros desta ordem caracterizam um ambiente urbano claramente poluído no que tange ao ruído ambiental. Observa-se que a referida lei não faz distinção em relação à distância das fontes emissoras de ruído, isto é, toda a área geográfica compreendida nos limites do zoneamento (Zona de Transição - BR 116 e Setor Especial - BR 116 para a região em estudo) deveria obedecer ao limite máximo permissível de $65 \mathrm{~dB}(\mathrm{~A})$ para o nível de pressão sonora equivalente no período diurno.

\section{IMPACTO AMBIENTAL DO RUÍDO GERADO PELO TRÁFEGO DE VEÍCULOS}

Com a reurbanização da antiga BR-116 para a Linha Verde, ocorreram várias mudanças na via, modificando algumas características da mesma: 1) tipo de pavimento, 2) velocidade média e a 3) composição do fluxo. A partir desta constatação, três cenários foram abordados para mostrar os níveis de ruído gerados em função dessas modificações. Foi escolhido o Ponto 17 como local do estudo.

\subsection{Tipo de pavimento}

No primeiro cenário, realizou-se um comparativo entre dois diferentes tipos de pavimento definidos pelo Software B\&K Predictor 7810, sendo um pavimento ruim (rugoso) mostrado na Figura 19 e um pavimento bom (liso) mostrado na Figura 20. 


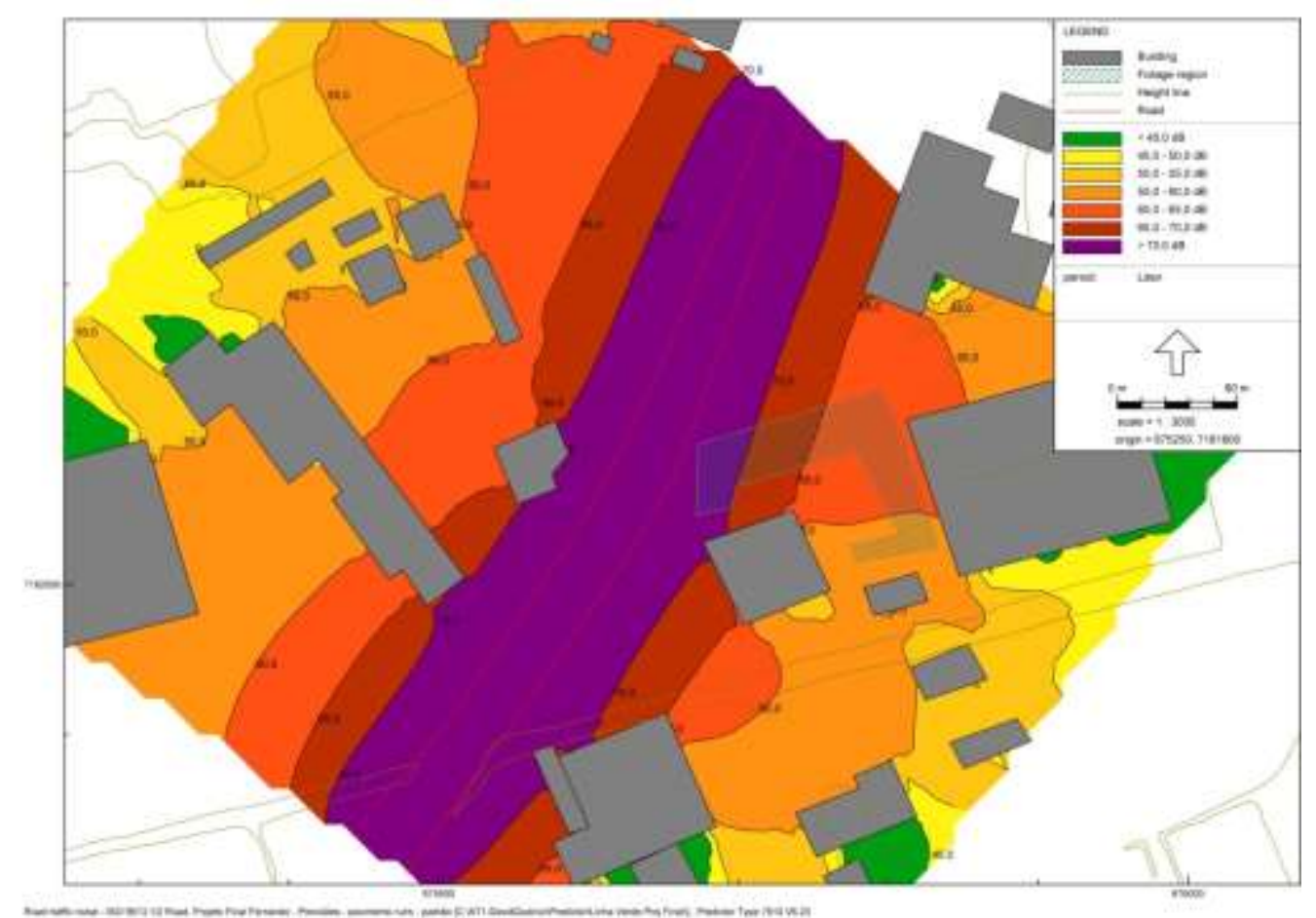

FIGURA 19: NÍVEIS DE PRESSÃO SONORA EQUIVALENTE OBTIDOS ATRAVÉS DO MAPEAMENTO DIGITAL - PAVIMENTO RUIM

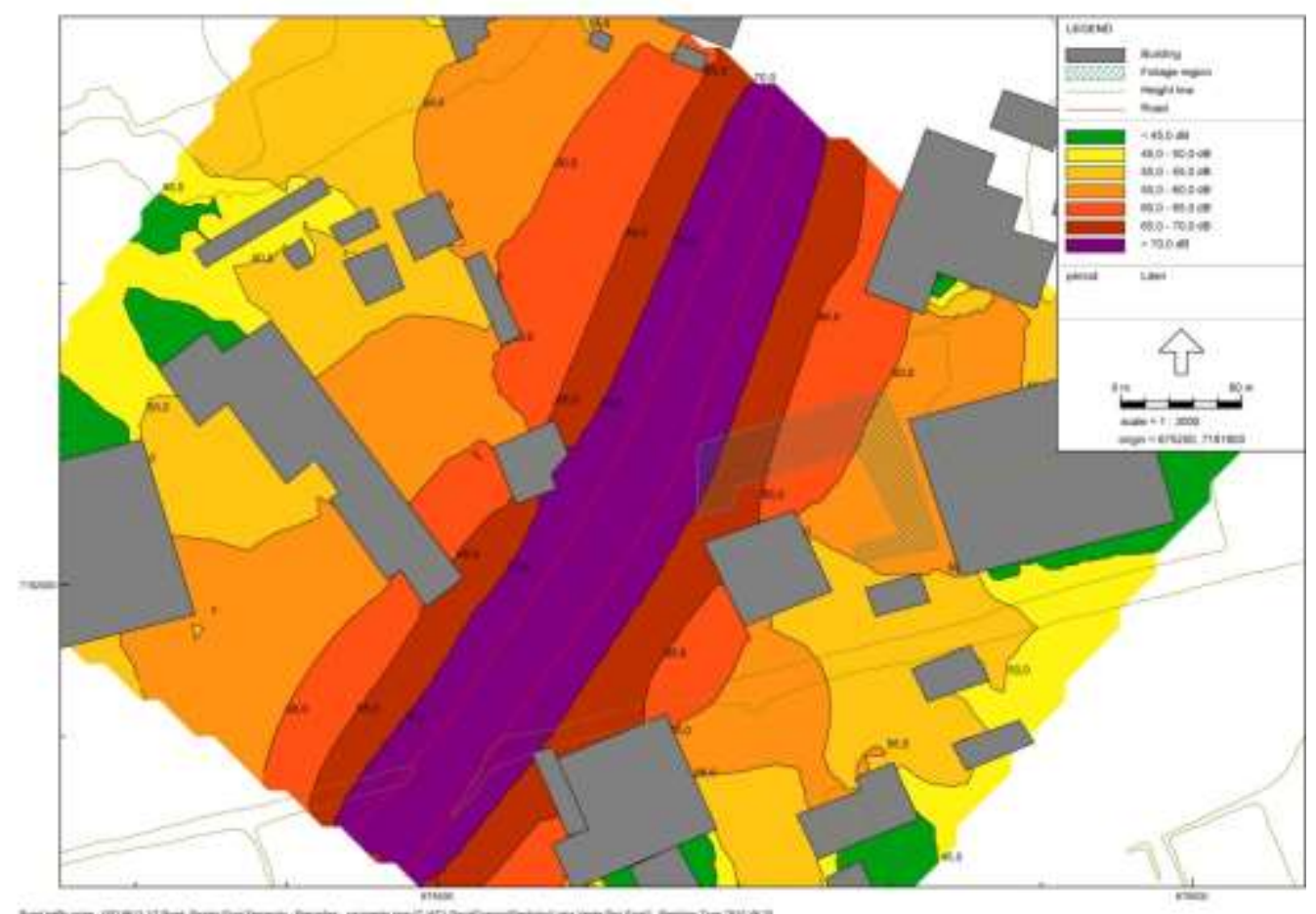

FIGURA 20: NÍVEIS DE PRESSÃO SONORA EQUIVALENTE OBTIDOS ATRAVÉS DO MAPEAMENTO DIGITAL - PAVIMENTO BOM. 
Com a melhoria do tipo de pavimento percebe-se uma diminuição dos níveis de pressão sonora no mapeamento acústico, verificando-se um estreitamento e diminuição dos níveis de ruído próximos à rodovia (ver a cor roxa, que representa a rodovia). Mantendo-se a velocidade constante, dois fatores são fundamentais na geração do ruído por veículos automotores: 1) o ruído gerado pelo motor, e 2) o ruído gerado pelo contato pneu/superfície (Landesanstalt für Umweltschutz - Baden-Württenberg, 1995). Portanto, o tipo de pavimento e a constante manutenção das vias de trafego são fatores decisivos na redução do ruído gerado em rodovias.

\subsection{VELOCIDADE MÉDIA}

No segundo cenário, entre duas velocidades médias de trânsito foram comparadas, sendo uma velocidade elevada a $100 \mathrm{~km} / \mathrm{h}$, Figura 21, e uma velocidade reduzida a $70 \mathrm{~km} / \mathrm{h}$, Figura 22. Estes valores da velocidade correspondem respectivamente às velocidades médias antes da Linha Verde e depois da Linha Verde.

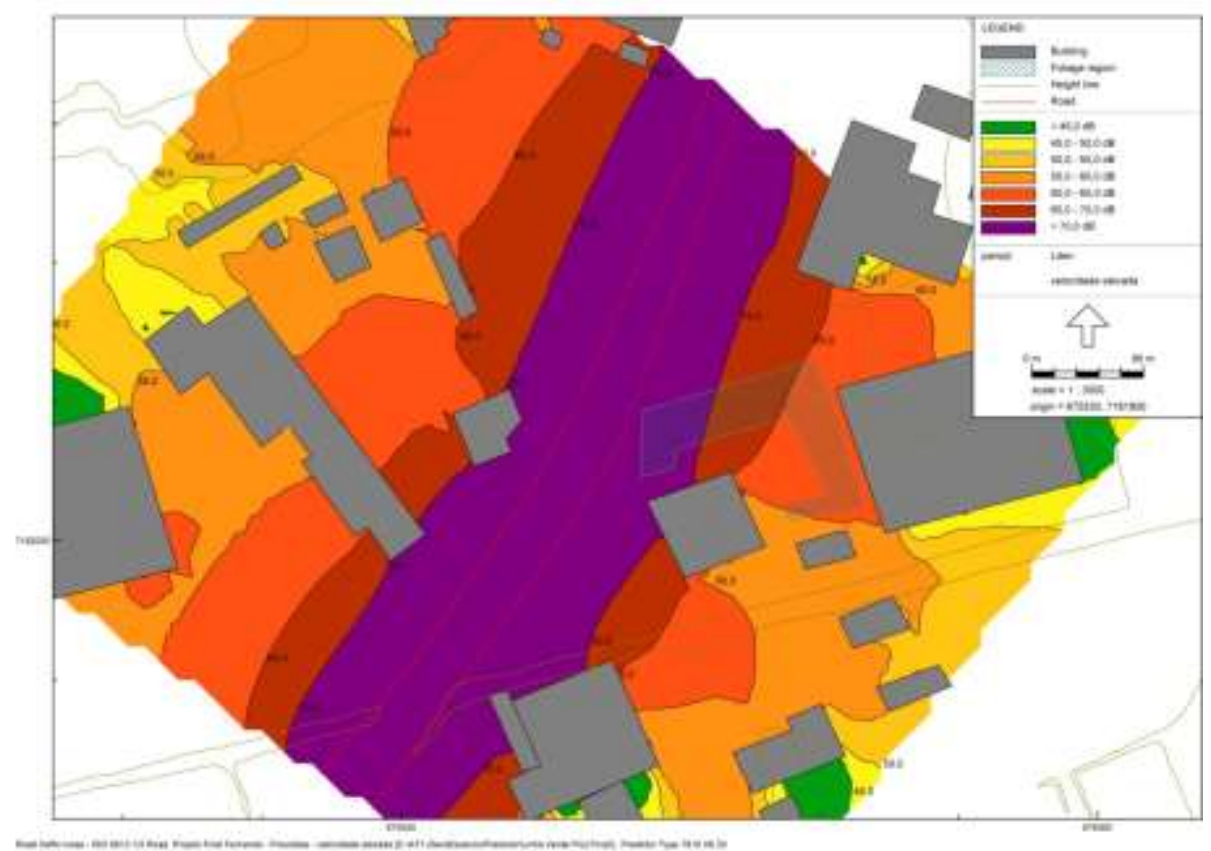

FIGURA 21: NÍVEIS DE PRESSÃO SONORA EQUIVALENTE OBTIDOS ATRAVÉS DO MAPEAMENTO DIGITAL - VELOCIDADE ELEVADA 


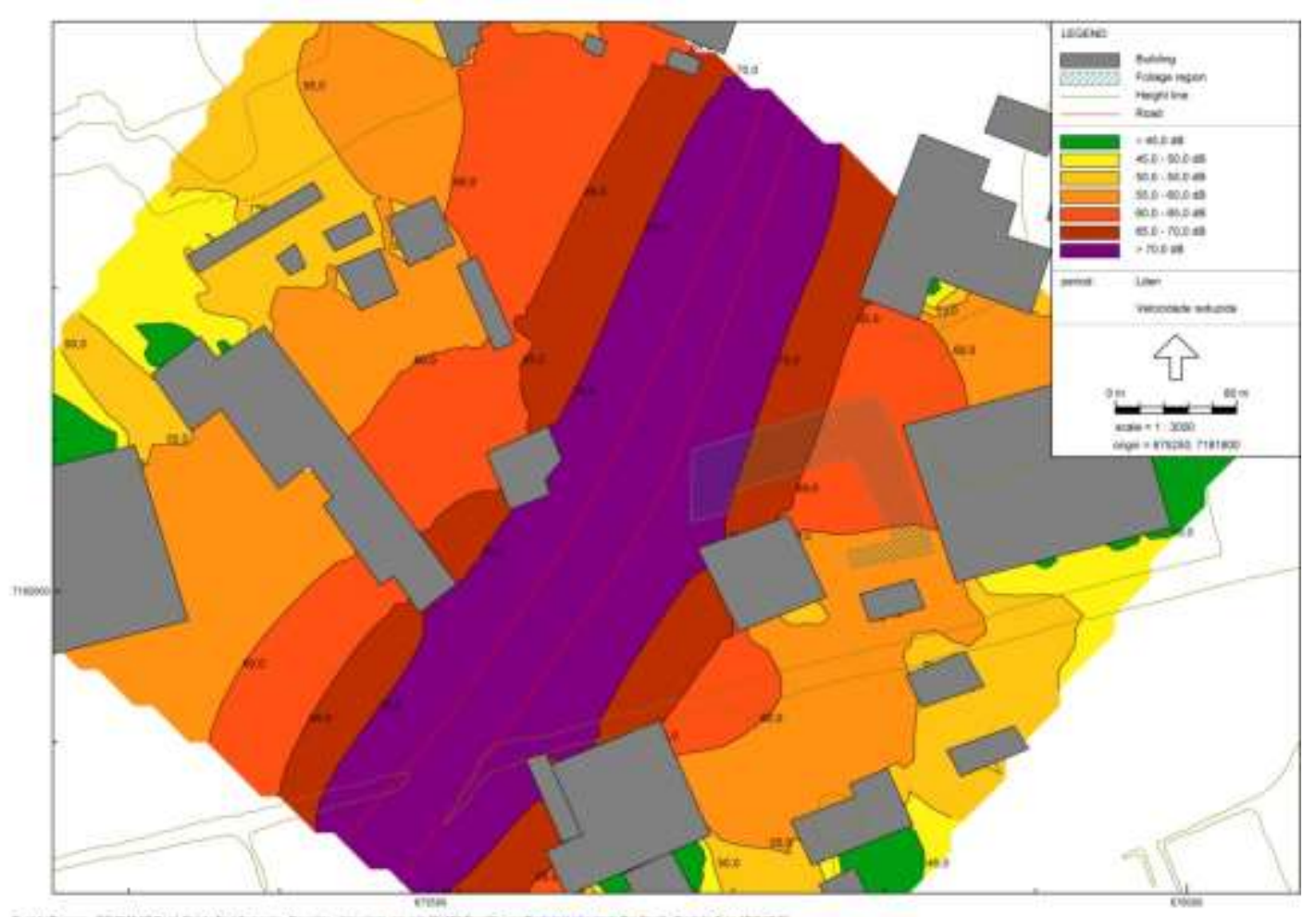

\section{FIGURA 22: NÍVEIS DE PRESSÃO SONORA EQUIVALENTE OBTIDOS ATRAVÉS DO MAPEAMENTO DIGITAL - VELOCIDADE REDUZIDA}

Com a diminuição da velocidade média percebe-se uma diminuição dos níveis de pressão sonora no mapeamento acústico. Esta diminuição pode ser vista pelo estreitamento e diminuição dos níveis de ruído próximos a rodovia.

\subsection{Composição do tráfego}

Neste cenário foi realizada a comparação entre os níveis sonoros gerados pela frota com a composição atual, que contem $18 \%$ de veículos pesados (Figura 23), e uma composição hipotética com 1\% de veículos pesados (Figura 24). Este percentual de 1\% é representado pelos veículos de transporte público. O cenário futuro para essa via contempla uma diminuição no número de veículos pesados de passagem, os quais passarão pelo contorno. 


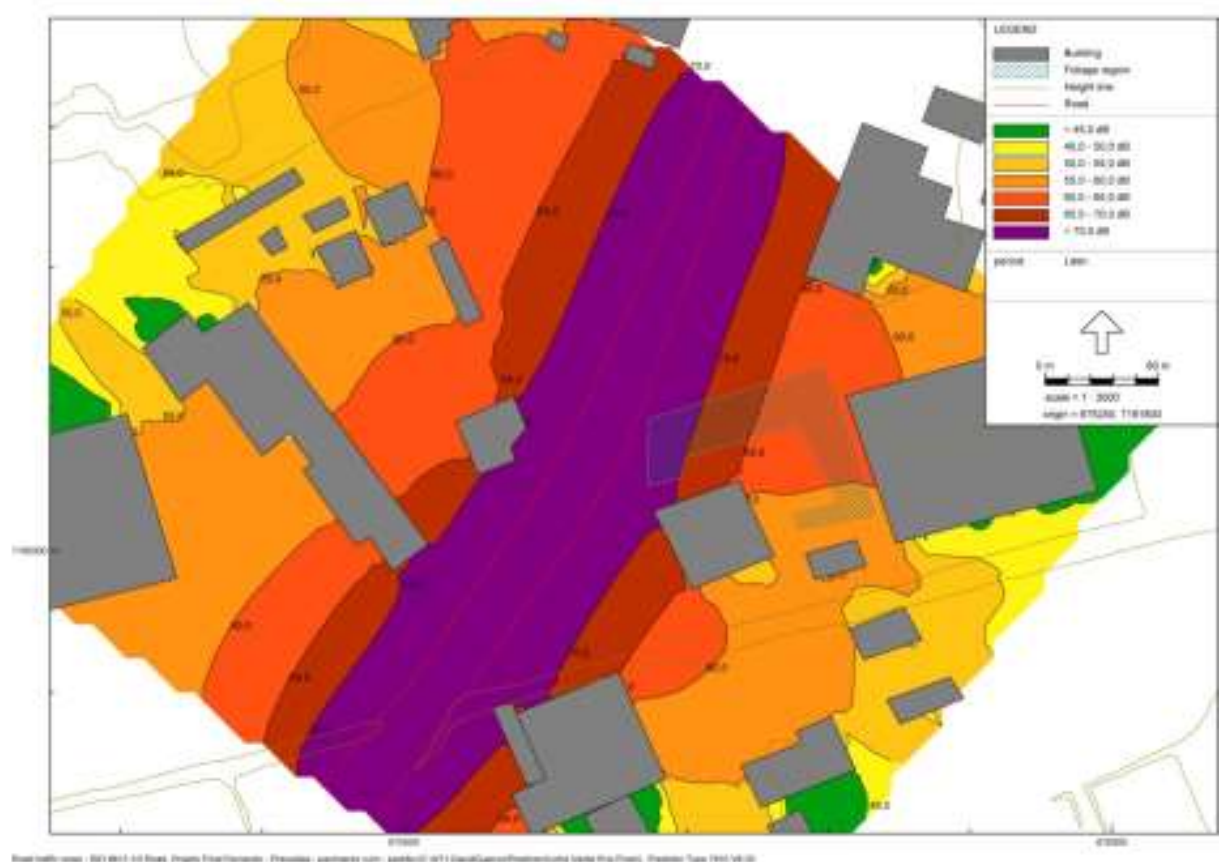

FIGURA 23: NÍVEIS DE PRESSÃO SONORA EQUIVALENTE OBTIDOS ATRAVÉS DO MAPEAMENTO DIGITAL - 18\% DE VEÍCULOS PESADOS (SITUAÇÃO ATUAL)

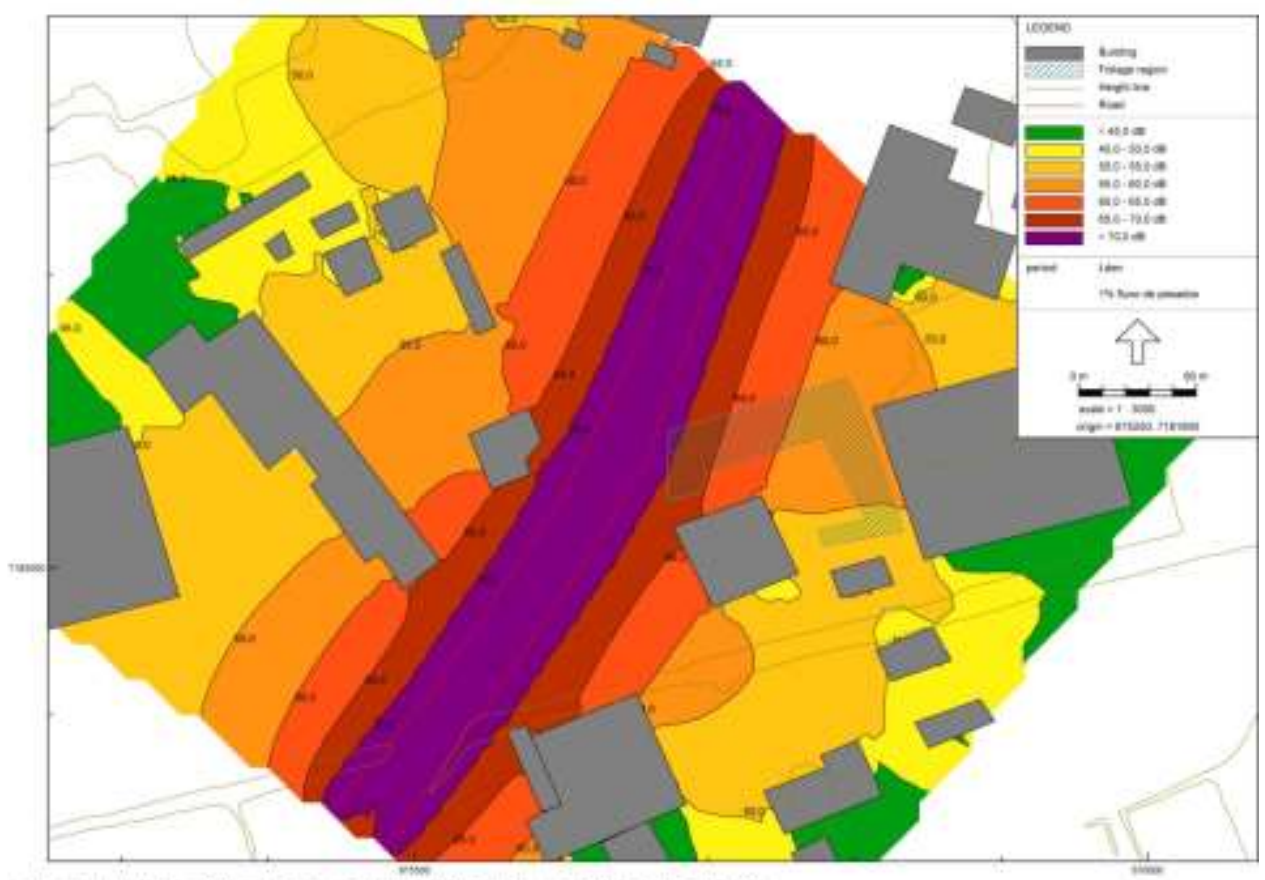

FIGURA 24: NÍVEIS DE PRESSÃO SONORA EQUIVALENTE OBTIDOS ATRAVÉS DO MAPEAMENTO DIGITAL - 1\% DE VEÍCULOS PESADOS

Com a diminuição do fluxo de veículos pesados na Linha Verde, percebe-se claramente uma diminuição dos níveis de pressão sonora no 
mapeamento acústico, verificando-se um estreitamento acentuado e uma diminuição acentuada dos níveis de ruído próximos a rodovia.

Através das simulações acima mostradas, percebe-se que há a necessidade da adoção de mais de uma medida mitigadora dos níveis de ruído. A redução do fluxo de veículos pesados foi a simulação que apresentou a diminuição mais acentuada nos níveis sonoros gerados em torno da via.

\section{CONCLUSÕES}

O tráfego de veículos na Linha Verde - Trecho Sul produz um impacto ambiental que resulta em níveis de poluição sonora inadequados às pessoas que vivem ou trabalham em torno desta via. O nível de ruído para todos os 24 pontos analisados está acima dos valores estabelecidos pela lei do município de Curitiba 10.625:02, que versa sobre o sossego da comunidade, ou seja, está acima de $65 \mathrm{~dB}(\mathrm{~A})$ no período diurno.

Através do estudo observou-se que a geração de ruído no local é constante e intensa, sendo o ruído fundamentalmente gerado pelo fluxo intenso de veículos leves (carros de passeio, utilitários) e veículos pesados (caminhões, ônibus).

Os mapas acústicos mostraram-se uma ferramenta importante na caracterização de grandes áreas atingidas pelo ruído, ajudando no planejamento da reestruturação de vias públicas (abertura, fechamento, desvios), já que permite prever o impacto sonoro que poderá ser causado.

Através da análise de três cenários hipotéticos, percebe-se que a melhoria em relação à poluição sonora está ligada não somente ao controle de ruído das fontes emissoras (veículos, caminhões, ônibus, etc.), mas também a medidas de planejamento e infraestrutura (conservação da qualidade das pistas por onde circulam os veículos, o uso de radares eletrônicos, conservação dos veículos através de leis que fiscalizem a emissão de ruídos). É necessário, portanto, parceria entre órgãos governamentais de planejamento, desenvolvimento urbano, transportes, meio ambiente, educação e comunidade científica para a mitigação do impacto causado pela poluição sonora e, 
consequentemente, a melhoria da qualidade vida das pessoas que habitam o meio ambiente urbano.

\section{AGRADECIMENTOS}

Os autores gostariam de agradecer ao CNPq e ao DAAD (Deutscher Akademischer Austauschdienst) Serviço Alemão de Intercâmbio Acadêmico, por fornecerem os meios financeiros para a compra do analisador sonoro e do software de simulação acústica, os quais foram fundamentais para a realização deste trabalho. Os autores gostariam de agradecer aos revisores por sua contribuição na melhoria do presente trabalho.

\section{REFERÊNCIAS BIBLIOGRÁFICAS}

ARANA, M.; GARCIA, A. A social survey on the effects on environmental noise on the residents of Pamplona, Spain. Applied Acoustic, 53: 245-53, 1998.

ALVES FILHO J.M.; LENZI A.; ZANNIN P.H.T. EFFECTS OF TRAFFIC COMPOSITION ON ROAD NOISE: A CASE STUDY. Transportation Research. Part D, Transport and Environment, v. 9, n.1, p. 75-80, 2004.

BELOJEVIC, G.; JACOVLEVIC, B.; ALESKSC, O. Subjective Reaction for Traffic Noisewith Regard to some Personality Traits. Environmental International, Yugoslavia, v. 23, n. 2, p. 221-226, 1997.

BERANEK, L. L. Noise Reduction, 1a․ ed. USA, 1960.

BRAMIGK D., KÜHNE R., VISSE L. Lärmfibel Strassenverkehr. Herausgeber: Deutscher Arbeitsring für Lärmbekämpfung e. V., Berlin, Dezember, 1992. (em alemão).

BIES, D. A.; HANSEN C. H. Engineering Noise Control: Theory and Practice. 2 ed. New York: Spon Press - Taylor \& Francis Group 2002.

$\mathrm{BABISCH}, \mathrm{W}$. The noise/stress concept, risk assessment and research needs. Noise Health, 4(16), 1-11, 2002. 
BRESSANE, A.; MOCHIZUKI, P. S.; CARAM, R. M. ; ROVEDA, J. A. F. . Zoneamento ambiental acústico como estratégia de gestão e controle da poluição sonora urbana. RA'E GA: o Espaço Geográfico em Análise, v. 35, p. 147-168, 2015.

BRONS, M. Railroad Noise: Economic Valuation and Policy. Transportation Research: Part D: Transport and Environment,8(3), 169-184, 2003.

BUNN, F.; FIEDLER, P.E.K.; ZANNIN, P.H.T. Avaliação da poluição sonora ambiental - normas e leis usadas no Brasil. Revista da Sociedade Brasileira de Acústica - SOBRAC, Rio de Janeiro, n.41, p. 47-54, 2009.

BUNN, F.; ZANNIN, P.H.T. Urban planning - Simulation of noise control measures. Noise Control Engineering Journal, 63 (1): 1-10, 2015.

CARTER, N.L. Transportation noise, sleep, and possible after-effects. Environ Int 1996, 22 (1):105-16.

DETRAN - Divisão de Estatística do Departamento de Trânsito do Governo do Estado do Paraná - Frota de veículos por tipo e Município 2007 - Disponível em<http://www.detran.pr.gov.br/arquivos/File/estatisticasdetransito/frotadeveicu loscadastradospr/2007/frotaveiculostipomunicipiooabriil2007.pdf.> Acesso em 12 de junho de 2010.

GAN, W. Q.; MCLEAN, K.; BRAUER, M.; CHIARELLO, S. A.; DAVIES H. W., Modeling population exposure to community noise and air pollution in a large metropolitan area, Environmental Research, Volume 116, 2012.

GRIFFITHS I.D; LANGDON, F. Subjective Effects of Traffic Noise Exposure, II: Comparisons of Noise Indices, Responses Scales, and the Effects of Changes in Noise Levels. Journal of Sound and Vibration, England, v. 83, n. 2, p. 171-180, 1982.

GAZETA DO POVO - Linha Verde tem novas regras para atrair investimentos $15 / 12 / 2015$. 
http://www.gazetadopovo.com.br/vida-e-cidadania/linha-verde (acesso em 27/07/2016).

INTERNATIONAL STANDARD ISO 9613-2 - Acoustis - Attenuation of Sound during propagation outdoors. Part 2: General method of calculation. Genève, Switzerland, 1996.

PAIVA-VIANNA K.M; CARDOSO, M.R.A.; RODRIGUES R.M.G.C. Noise pollution and annoyance: An urban soundscapes study. Noise \& Health, v. 17 , p. $125,2015$.

LANDESANSTALT FÜR UMWELTSCHUTZ BADEN-WÜRTTENBERG, ISSN: 0939-8236, 1995. (Em Alemão) (Secretaria do Meio Ambiente do Estado de Baden-Württenberg).

MURPHY E., KING E.A. Strategic environmental noise mapping: Methodological issues concerning the implementation of the EU Environmental Noise Directive and their policy implications. Environment International 36 (2010) 290-298.

MURPHY E., KING E.A. Scenario analysis and noise action planning: Modelling the impact of mitigation measures on population exposure. Applied Acoustics 72, 487-494, 2011.

PMC - PREFEITURA MUNICIPAL DE CURITIBA - SECRETARIA MUNICIPAL DO MEIO AMBIENTE - CURITIBA (SMMA). Lei No. 10.625, de 19 de fevereiro de 2002. Dispõe sobre ruídos urbanos, proteção do bem estar e do sossego público e dá outras providências. Diário Oficial do Estado do Paraná, 9 p., 2002.

PAZ, E. C.; FERREIRA, A. C.; ZANNIN, P. H. T. Estudo comparativo da percepção do ruído urbano. Revista de Saúde Pública, v. 39, p. 467-472, 2005. 
PAZ, E. C.; ZANNIN, P. H. T. Urban daytime traffic noise prediction models. Environmental Monitoring and Assessment (Print), v. 163, p. 515-529, 2010.

PAZ, E. C.; ZANNIN, P. H. T. Avaliação do ruído de tráfego noturno Estudo de Caso na cidade de Curitiba, Brasil. RA'E GA: o Espaço Geográfico em Análise, v. 31, p. 29-52, 2014.

RLS - 90 - RICHTLINIEN FÜR DEN LÄRMSCHUTZ AN STRASSEN. (1990). (Diretrizes para o controle do ruído em rodovias). DER BUNDESMINISTER FÜR VERKEHR (Ministério dos Transportes da Alemanha). (Em alemão).

ROMEU J., GENESCÀ, M., PÀMINES, T., JIMÉNEZ S. (2011). Street categorization for the estimation of day levels using short-term measurements. Applied Acoustics,72, 569-577.

SCHAFER, R. M. A Afinação do Mundo. Fundação Editora da UNESP, São Paulo - SP, 1997.

SANTOS DE SOUZA, R. Entendendo a questão ambiental.. Edunisc - Santa Cruz do Sul,2000

SZEREMETA, B., ZANNIN, P.H.T. Analysis and evaluation of soundscapes in public parks through interviews and measurement of noise. Science of the Total Environment, v. 407, p. 6143-6149, 2009.

WG-AEN - EUROPEAN COMMISSION WORKING GROUP ASSESSMENT OF EXPOSURE TO NOISE (WG-AEN): "Good Practice Guide for Strategic Noise Mapping and the Production of Associated Data on Noise Exposure"- version 2, page 1-129, 13th January 2006.

ZANNIN P.H.T., CALIXTO A., DINIZ F. B. D., BARBOSA W. A. Enviromental Noise Pollution in Residencial Areas of the City of Curitiba. Acústica Acta Acústica, Alemanha, 87: 625-628, 2001. 
ZANNIN P.H.T., CALIXTO A., DINIZ F. B. D., FERREIRA J. A. C., SCHULLER R. Incômodo Causado pelo Ruído Urbano à População de Curitiba, PR. Revista de Saúde Pública, São Paulo, v.36, n. 4, p. 521-524, 2002.

ZANNIN, P. H. T.; SANT'ANA, D. Q., Noise mapping at different stages of a freeway redevelopment project - A case study in Brazil, Applied Acoustics, 72 (8): 479-486, 2011.

ZANNIN P. H. T.; ENGEL M.; FIEDLER; PEK; BUNN, F. Characterization of environmental noise based on noise measurements, noise mapping and interviews: A case study at a university campus in Brazil. Cities 31, 317327, 2013. 